\title{
EL LIBRO DE SEPULTURAS DEL MONASTERIO DE SANTA MARÍA MAGDALENA DE SARRIA ${ }^{1}$
}

\author{
Por \\ ROSA M MÁZQUEZ SANTOS
}

La documentación conservada en el Archivo Histórico Nacional sobre el monasterio de Sta. $M^{\mathrm{a}}$ Magdalena de Sarria apenas ha aportado datos que iluminen su historia y avatares artísticos durante la Edad Moderna, época en la que fue uno de los hitos más relevantes del Camino Francés ${ }^{2}$. El libro que nos ocupa no sólo ha cubierto ese vacío, aportando numerosas descripciones y datos relativos al monasterio, sino que, a través de sus dibujos, ha enriquecido su patrimonio al constituir en sí mismo una pequeña obra de arte.

El libro de sepulturas fue realizado en Sarria por un padre agustino, el P. Mosquera, en el año $1705^{3}$, siendo prior Fray Antonio de Castro ${ }^{4}$. Se trata de un registro de las sepulturas de la iglesia conventual «asi dotadas como por dotar, nichos y capillas que tiene este Convento de la Malena de Sarria».

\footnotetext{
${ }^{1}$ Convento de la Merced desde 1896.

${ }^{2}$ Véase SEIJAS VÁZQUEZ, E y LOSADA DÍAZ, A: Guía del Camino Francés en la provincia de Lugo, Lugo, 1966, pg. 94 y ss. y VÁZQUEZ SACO, F.: Sarria en el Camino francés de las peregrinaciones, B.C.P.M.L., 1945, pg. 93 y ss.

${ }^{3}$ SARRIA, A.C.M., Libro de Sepulturas, s/f.

${ }^{4}$ «Abarca su gobierno el trienio 1704-1706» (VÁZQUEZ SACO, F.: Los Priores, B.S.E.S., 1988, pg. 19).

${ }^{5}$ SARRIA, A.C.M., Libro de Sepulturas, s/f.
}

"CUADERNOS DE ESTUDIOS GALLEGOS", Tomo XLV, Fascículo 110, Santiago 1998. 
La obra cuenta con varias hojas sin foliar, añadidas con posterioridad, en las que se recogen datos sobre las obras y arreglos llevados a cabo en la iglesia a lo largo del S. XVIII, y 193 foliadas, divididas en tres registros de sepulturas, misas cantadas y misas rezadas.

El registro de sepulturas es el más extenso y su estructura «sigue la tabla de las yleras (de sepulturas) que hay en la Capilla Mayor y Cuerpo de la Yglesia, Capilla de San Lorenço, Capilla del Santo Xpristo, Capilla de Nuestra Señora de Graçia, y Capilla de San Joseph ${ }^{6}$. El recto de las hojas se decora con un marco rectangular, cuyos lados se construyen con sogas unidas en los ángulos por motivos circulares y pequeñas espirales, en cuyo interior se anotan los nombres de quienes están enterrados en las diferentes sepulturas, mientras que el vuelto, sin decorar, se reserva para anotar las dotaciones y rentas con que estas cuentan.

Como ya he enunciado el libro incluye, además, numerosos dibujos o apuntes gráficos, estos reproducen escudos de armas, nichos, retablos, altares, pilas, púlpitos, arcos... y todos aquellos elementos constructivos o muebles que puedan servir como punto de referencia para situar las sepulturas dentro de la iglesia conventual. En consecuencia, la obra es una fuente de gran interés para el conocimiento de la historia del monasterio y de la propia villa de Sarria.

\section{PROMOTORES Y PATRONOS}

Por un lado, a través de las fundaciones y dotaciones que en el libro se recogen, se nos informa sobre los principales promotores y patronos del convento, pertenecientes a los linajes de mayor renombre de la comarca. Así, el P. Mosquera, aporta datos sobre la relación que, a lo largo de los siglos, los Condes de Lemos han mantenido con la Magdalena de Sarria, desde que a comienzos del XVI se construye el nicho alto de la capilla mayor $^{7}$, hermoso arco de estilo manuelino ${ }^{8}$, con el fin de que si «el Señor

${ }^{6}$ SARRIA, A.C.M., Libro de Sepulturas, s/f.

${ }^{7}$ Nicho que el P. Mosquera dibuja coronado por dos escudos que exhiben los seis roeles de los Castros, véase: SARRIA, A.C.M., Libro de Sepulturas, fol. 20r.

${ }^{8}$ Ideado como arcosolio se transformaría más tarde en una singular ventana, véase SOLLA FONTÁN, L.J.: El Convento de la Merced. Monasterio de la Magdalena de Sarria, León, 1996, pg. 29.

"CUADERNOS DE ESTUDIOS GALLEGOS", Tomo XLV, Fascículo 110, Santiago 1998. 


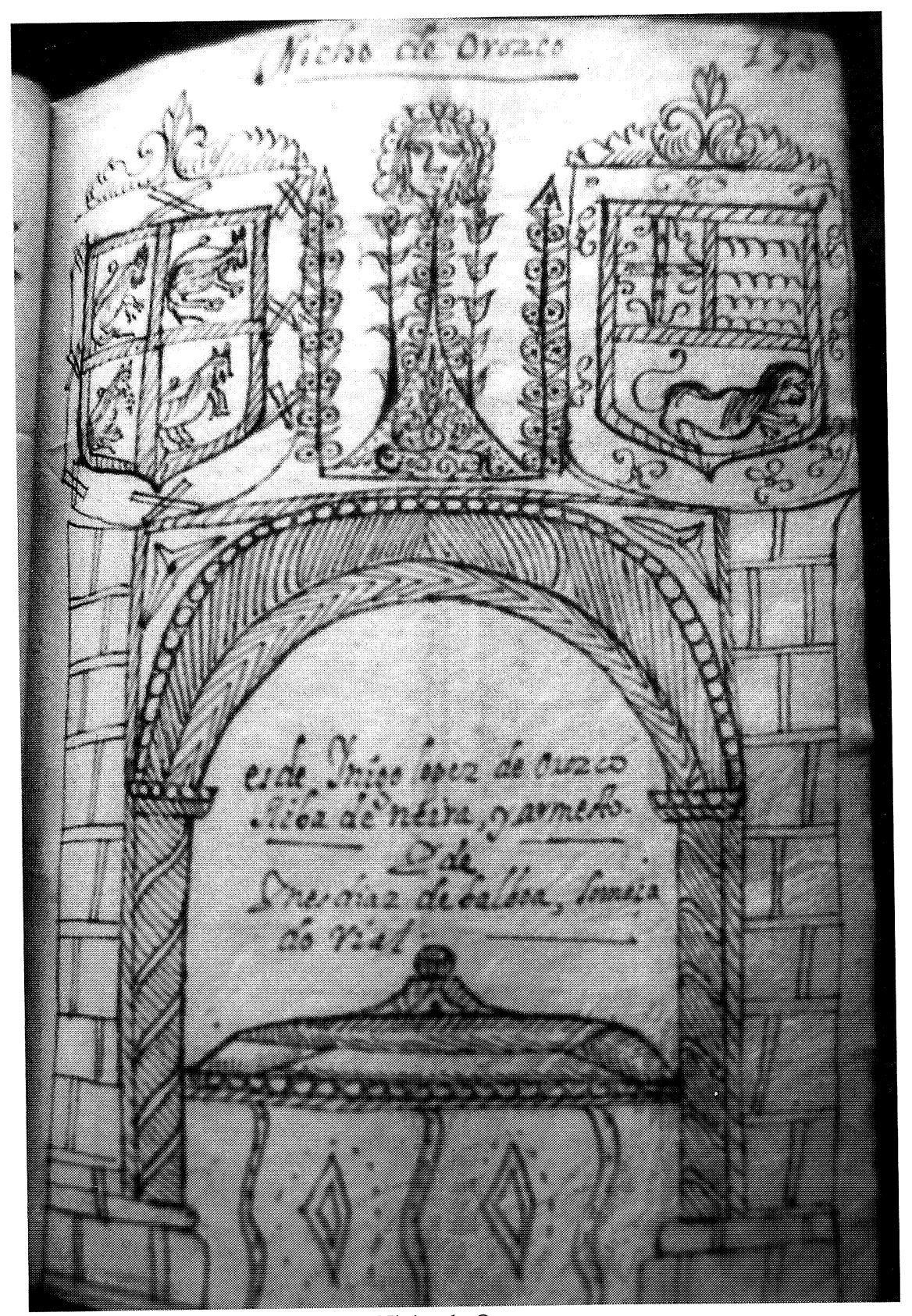

Nicho de Orozco.

(Sarria, A.C.M., Libro de Sepulturas, 153r.) 
conde de lemos quissiese tomar el patronato deste convento serviesse para su excelencia dicho nicho» ${ }^{9}$ y D. Rodrigo Enríquez Osorio funda una misa cantáda en el altar de Nuestra Señora de Gracia $^{10}$, hasta que en el S. XVII, con D. Francisco Fernández de Castro y Andrade, se concierta finalmente el patronato de los Condes de Lemos sobre el monasterio de la Magdalena ${ }^{11}$.

Otra figura capital para el monasterio de Sarria fue el maestreescuela de la catedral de Orense Nuño Álvarez de Guitián ${ }^{12}$, cuya sepultura, arcosolio con urna sepulcral y escudo cuartelado estudiado por el profesor Chamoso Lamas ${ }^{13}$, aparece dibujada en el libro de sepulturas ${ }^{14}$, y del que el P. Mosquera nos dice fue gran benefactor del monasterio pues « $a$ su costa hiço dicho maestre dicha Capilla Mayor» ${ }^{15}$.

También entre los próceres y promotores del monasterio tenemos noticia de los Señores del Castillo de los Infantes ${ }^{16}$ y D. Íñigo López de Orozco $^{17}$, cuyos sepulcros, ricos arcosolios de factura gótica coronados por escudos de armas y estudiados también por Chamoso Lamas ${ }^{18}$, aparecen reproducidos con detalle en el libro de sepulturas ${ }^{19}$.

${ }^{9}$ SARRIA, A.C.M., Libro de Sepulturas, fol. 20v.

${ }^{10}$ Don Rodrigo Enríquez Osorio, conde de Lemos, fundó una misa cantada a Nuestra Señora «con Responso todos los sabados... cediendonos para este efecto el Patronato de San Martin de Loseyro para siempre jamas» (SARRIA, A.C.M., Libro de Sepulturas, fol. 167r.)

${ }^{11}$ Patronato sellado de acuerdo con la escritura otorgada el 27 de julio de 1643, (véase VÁZQUEZ SACO, F.: Los Escudos de Sarria, Lugo, 1953, pg. 10), y recogido por el P. Mosquera en relación con el juicio que por dicho patronato, que enfrentó a los agustinos con los descendientes de Nuño Álvarez de Guitián (SARRIA, A.C.M., Libro de Sepulturas, fol. 20v).

${ }^{12}$ Nacido en la casa señorial de San Saturnino de Froyán (Sarria) realizó su manda testamentaria en el año 1511, véase VÁZQUEZ SACO,: Ob. cit., 1953, pg. 9.

${ }^{13}$ CHAMOSO LAMAS, M.: Escultura Funeraria en Galicia, Orense, 1979, pg. 313 y ss.

${ }^{14}$ SARRIA, A.C.M., Libro de Sepulturas, fol. 22r.

${ }^{15}$ SARRIA, A.C.M., Libro de Sepulturas, fol. 20v.

${ }^{16}$ Emparentados con la Casa de Lemos y otros linajes principales de la comarca de Sarria, véase VÁZQUEZ SACO, F.: Ob. cit., 1953, pg. 12.

${ }^{17}$ Quien legó cuantiosos bienes y rentas al monasterio en su testamento otorgado el 10 de Abril de 1516, véase VÁZQUEZ SACO, F.: Ob. cit., 1953, pg. 13.

${ }^{18}$ CHAMOSO LAMAS, M.: Ob. cit., pg. 315 y ss.

${ }^{19}$ SARRIA, A.C.M., Libro de Sepulturas, fol. 122r y $153 \mathrm{r}$.

"CUADERNOS DE ESTUDIOS GALLEGOS", Tomo XLV, Fascículo 110, Santiago 1998. 
El P. Mosquera aporta además dibujos de escudos de armas que, aunque no tienen presencia física en el convento, pertenecen a algunos de los grandes señores que en él han recibido sepultura como el Licenciado de Cuéllar $^{20}$, el Duque de Arsona ${ }^{21}$, D. Carlos de Balcárcel ${ }^{22}$ y los Señores de Requeijo ${ }^{23}$.

\section{ALTARES Y RETABLOS}

Pero esta obra aún posee mayor interés para el conocimiento de los altares y retablos de la iglesia conventual. De algunos de estos retablos, en parte o totalmente desaparecidos, sólo nos han quedado los apuntes y dibujos del P. Mosquera, convirtiéndose en fuente privilegiada para su estudio, y sobre los que todavía se conservan, de factura más reciente, nos ha aportado fechas y datos relativos a su construcción, pintura, dorado y traslados dentro de la iglesia.

La propia estructura del libro nos indica las capillas y altares que conformaban la iglesia, de ellas destaca el autor de los retablos de la capilla mayor, capilla de S. José, capilla de Sto. Cristo y capilla de Ntra. $S^{a}$ de Gracia, de los que realiza dibujos a toda página.

El dibujo del retablo de la capilla mayor ${ }^{24}$, realizado como todos en 1705 , nos muestra una estructura sin banco, con dos cuerpos divididos en tres calles por columnas salomónicas y un remate o ático formado por dos escudos agustinos en los extremos, dos adornos en forma de candelabros, y en el centro, una cruz desnuda entre la espada y la pluma ${ }^{25}$. De este retablo se conserva en el actual parte de su estructura pero le fueron añadidos un ático semicircular, columnas y numerosos elementos decorativos en $1763^{26}$.

\footnotetext{
${ }^{20}$ SARRIA, A.C.M., Libro de Sepulturas, fol. 23 r.

${ }^{21}$ SARRIA, A.C.M., Libro de Sepulturas, fol. 26r.

${ }^{22}$ SARRIA, A.C.M., Libro de Sepulturas, fol. 27r.

${ }^{23}$ SARRIA, A.C.M., Libro de Sepulturas, fol. 170r.

${ }^{24}$ SARRIA, A.C.M., Libro de Sepulturas, fol. 1r.

${ }^{25}$ Véase SOLLA FONTÁN, L.J.: Ob. cit., pg. 32.

${ }^{26}$ En este año «se hizo nuevo el remate de la Capilla Mayor, el Camarín, y Custodia, con toda la Gradería, credencias, adorno de columnas, y se doró todo el dicho Retablo, y retocaron todas las imágenes de los Santos de dicho Altar». (SARRIA, A.C.M., Libro de Sepulturas, s/f).
}

"CUADERNOS DE ESTUDIOS GALLEGOS", Tomo XLV, Fascículo 110, Santiago 1998. 


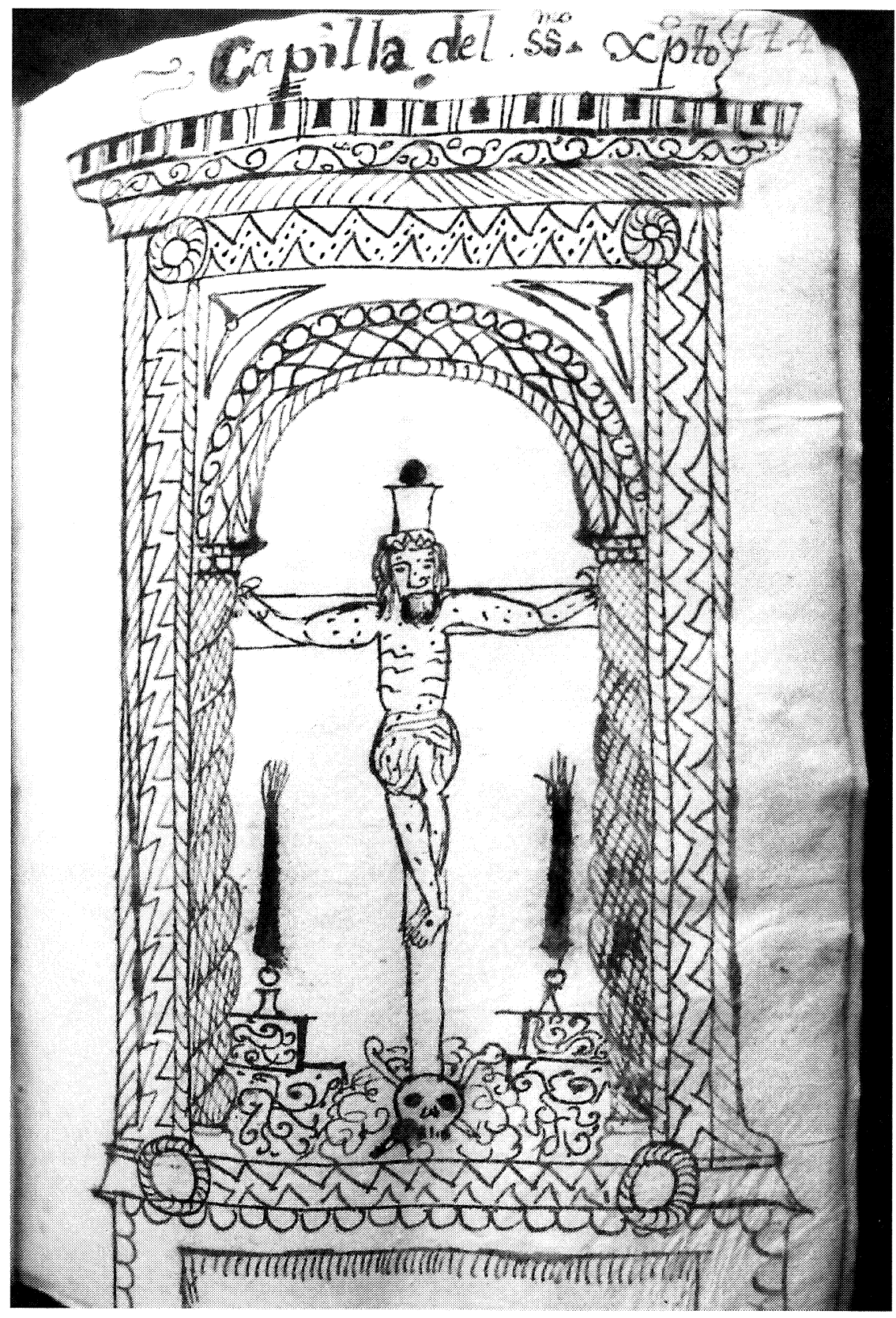

Escudo de armas de los señores de Requeijo.

(Sarria, A.C.M., Libro de Sepulturas, 170r.) 


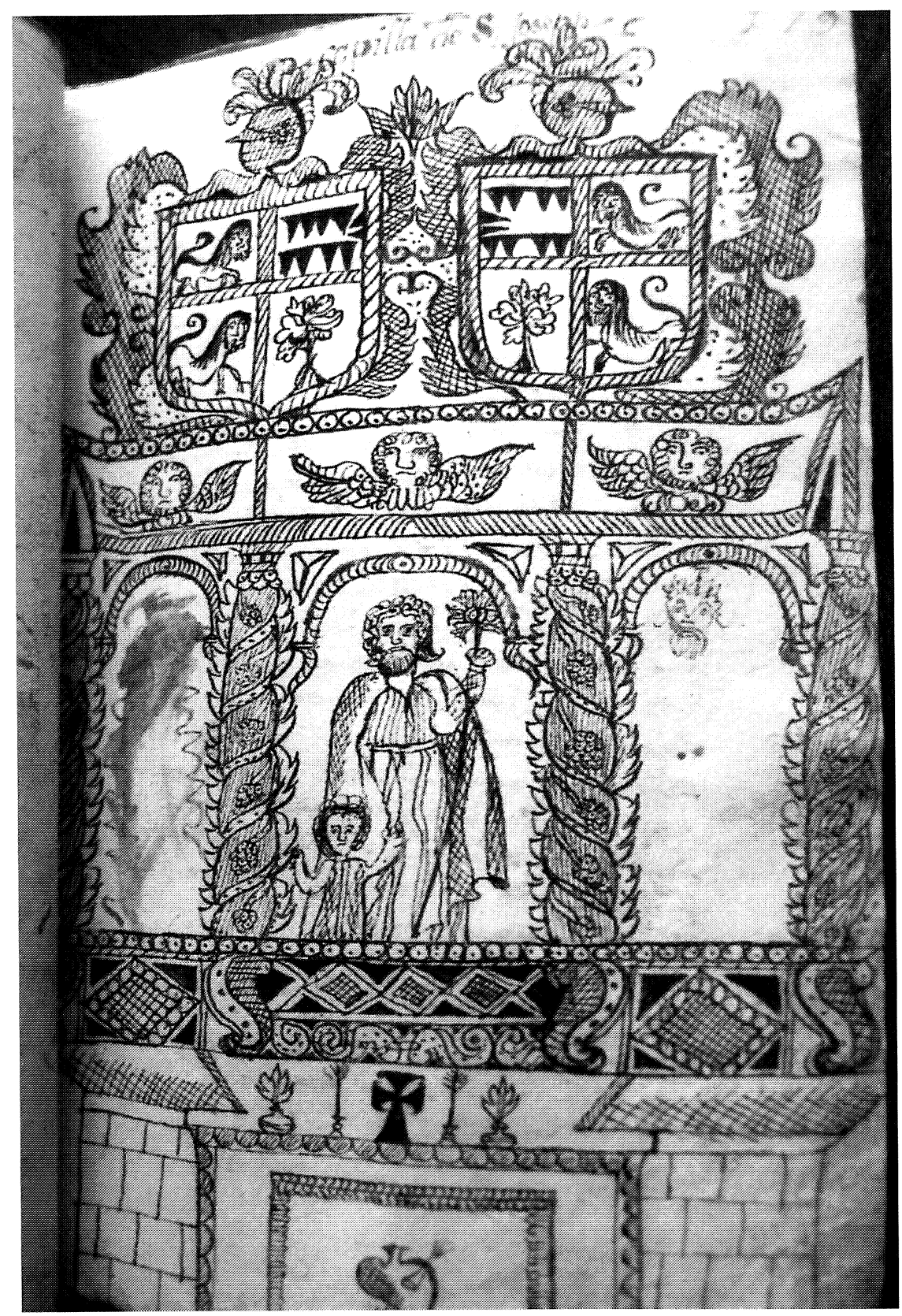

Capilla de S. José.

(Sarria, A.C.M., Libro de Sepulturas, 179r.) 


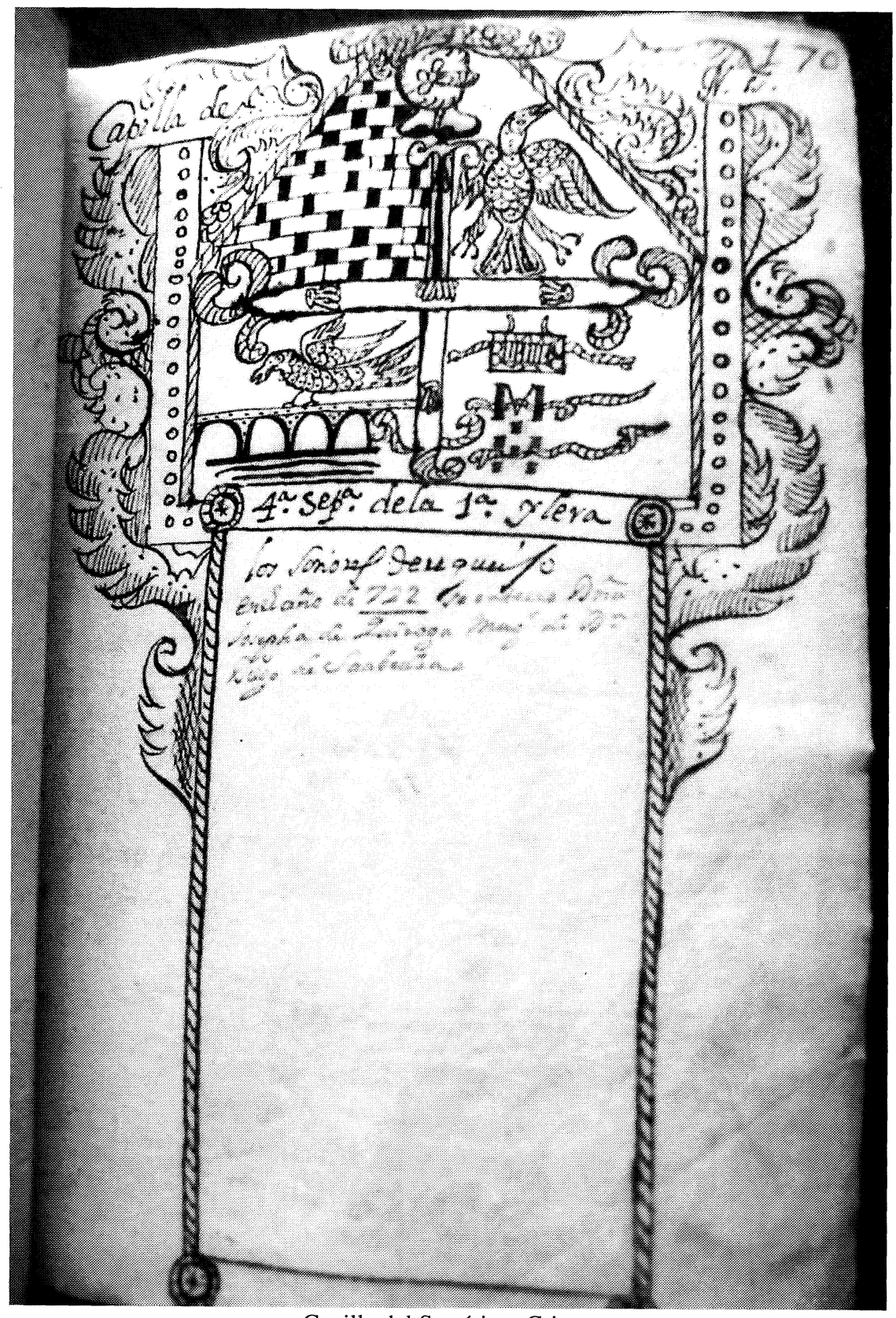

Capilla del Santísimo Cristo.

(Sarria, A.C.M., Libro de Sepulturas, 114r.) 
Unida por un arco a la capilla mayor, lado del evangelio, se encuentra la capilla del Sto. Cristo cuyo retablo barroco acoge en su único nicho un calvario completo. En el dibujo del P. Mosquera ${ }^{27}$ aparece el mismo retablo pero tan solo la imagen del crucificado flanqueado por dos candelabros pues, como se nos indica en las notas añadidas al comienzo del libro, no se completaría el Calvario hasta que en el año 1797 «se compuso y doró y retocaron las imágenes que antes eran remate de el Altar Mayor ${ }^{28}$, imágenes éstas de S. Juan y de la Virgen Dolorosa ${ }^{29}$.

En otra de las capillas principales del monasterio, la de S. José en $^{30}$ se encontraba el retablo de su advocación, reproducido en uno de los dibujos $^{31}$ con banco, cuerpo único dividido en tres calles flanquedas por cuatro columnas salomónicas, cornisa y remate formado por dos grandes escudos cuartelados, de el que nada se conserva. El que hoy existe fue construido para esta capilla de S. José en 1766, retablo rococó con columnas panzudas y decoración a base de rocallas, paños y colgaduras ${ }^{32}$ que «se doro y pinto año de 1797»" .

El último de los retablos dibujados por el P. Mosquera es el de Ntra. $S^{a}$ de la $\mathrm{Gracia}^{34}$, que se hallaba en la capilla situada entre el crucero y la de S. Lorenzo. Este retablo barroco, con banco, un único cuerpo de tres calles separadas por columnas salomónicas y planta trapezoidal ${ }^{35}$, fue trasladado en 1797 a la capilla de S. Lorenzo ${ }^{36}$ por lo que «el Retablo de Nuestra Señora se hizo todo nuevo, y tambien... se doro y pinto ${ }^{37}$.

${ }^{27}$ SARRIA, A.C.M., Libro de Sepulturas, fol. 114r.

${ }^{28}$ SARRIA, A.C.M., Libro de Sepulturas, s/f.

${ }^{29}$ Con ellas se completaría el primitivo calvario del que las tallas que hoy podemos ver son réplica, véase SOLLA FONTÁN, L.J.: Ob. cit., pg. 37.

${ }^{30}$ Hoy capilla del Sagrado Corazón, véase SOLLA FONTÁN, L.J.: Ob. cit., pg. 34.

${ }^{31}$ SARRIA, A.C.M., Libro de Sepulturas, fol. 179r.

${ }^{32}$ SARRIA, A.C.M., Libro de Sepulturas, fol. 179v

${ }^{33}$ SARRIA, A.C.M., Libro de Sepulturas, s/f.

${ }^{34}$ SARRIA, A.C.M., Libro de Spulturas, fol. 166r.

${ }^{35}$ En dibujo del P. Mosquera las calles laterales se presentan en escorzo sugiriendo esta planta.

${ }^{36}$ Después de que «se compuso para el sitio... se renovó, doró y pintó año de 1797» (SARRIA, A.C.M., Libro de Sepulturas, s/f).

${ }^{37}$ SARRIA, A.C.M., Libro de Sepulturas, s/n.

"CUADERNOS DE ESTUdIOS GALLEGOS", Tomo XLV, Fascículo 110, Santiago 1998. 


\section{LA ARQUITECTURA Y OTRAS ACTIVIDADES ARTÍSTICAS}

En lo referente a la arquitectura, el libro, en sus notas añadidas a lo largo del S. XVIII, nos informa de las obras llevadas a cabo en la capilla mayor ${ }^{38}$; en la capilla del Santo Cristo $^{39}$ y en la capilla de S. Lorenzo ${ }^{40}$. Sin embargo no recoge ningún dato acerca de las obras de ampliación del monasterio realizadas en el año de $1776^{41}$ mientras que describe minuciosamente el hospital viejo, edificio situado frente al monasterio con capilla y espacio para atender a los peregrinos ${ }^{42}$ que fue derribado en $1786^{43}$, y los hospitalillos y plazuela nuevos, construidos en $1777^{44}$.

En otros campos, sin embargo, los datos que el libro nos aporta son mínimos. Así, en relación con la orfebrería, tan solo se recoge la donación de un crucifijo y candeleros de bronce para la capilla de S. José por D. Lucas Somoza, patrón de la capilla, en el año $1766^{45}$.

Pero no obstante, hemos de destacar la existencia de datos y apuntes relativos a todas las actividades artísticas, lo que lleva al autor a reproducir las pilas de agua bendita ${ }^{46}$, el púlpito ${ }^{47}$, y diferentes piezas de mobiliario litúrgico.

${ }^{38}$ «en el año de 1765 se levantó... y lo que antes tocaba a Presbiterio, y Sepulturas de Religiosos, se hizo todo Presbiterio» (SARRIA, A.C.M., Libro de Sepulturas, s/f).

39 «se rebajo, y embaldoso, y quitaron las rejas, el mismo 1765» (SARRIA, A.C.M., Libro de Sepulturas, s/f).

${ }^{40}$ «se embaldoso de Pizarras» (SARRIA, A.C.M., Libro de Sepulturas, s/f).

${ }^{41}$ VÁZQUEZ SANTOS, R.: Aportación documental sobre la actividad artística en el Camino Francés entre los años 1500-1800 (O Cebreiro-Portomarín), Tesina inédita, pg. 329.

${ }^{42}$ «una casa grande con su Capilla terrena, y coro alto, y debajo de este (dividido de la Capilla con Balaustrado de Madera) avia sitio para las camas de los peregrinos bastante capaz... Avia tambien Quarto alto para el Hospitalario, con Cocina baja separada de este» (SARRIA, A.C.M., Libro de Sepulturas, s/f)

${ }^{43}$ VÁZQUEZ SANTOS, R.: Ob. cit., pg. 349.

${ }^{44}$ «Por los años de 1777 se Hizieron los Hospitalillos nuevos... En lo demás quedó la Plazuela y camino que esta enfrente de los Hospitalillos» (SARRIA, A.C.M., Libro de Sepulturas, s/f)

${ }^{45}$ SARRIA, A.C.M., Libro de Sepulturas, fol. 179v.

${ }^{46}$ SARRIA, A.C.M., Libro de Sepulturas, fol. 57r.

${ }^{47}$ SARRIA, A.C.M., Libro de Sepulturas, fol. $41 \mathrm{r}$.

"CUADERNOS DE ESTUDIOS GALLEGOS", Tomo XLV, Fascículo 110, Santiago 1998. 